\title{
Saberes científicos e epistemologia da prática nos processos institucionais de formação docente e de formação de leitores
}

\author{
Zizi Trevizan*1
}

\section{Resumo}

Com o objetivo de repensar o processo de formação do professor da Educação Básica, configurado no cotidiano das Instituições de Ensino Superior e nas vivências profissionais continuadas, a pesquisa relatada neste artigo utiliza uma metodologia qualitativa (entrevista semiestruturada) e discute a história de formação e vivências de duas professoras graduadas em Letras e Pedagogia, atuantes no ensino da leitura no estado paulista. O estudo, de aporte teórico bakhtiniano, histórico-cultural, apresenta, na sua amostragem, a carência teórica e prática do formador de leitores e as conclusões apontam para o desafio de um investimento articulado (Estado, Universidade, Escola Básica) na formação identitária (cultural, científica, pedagógica) do professor, para um desempenho mais eficaz no processo de formação de leitores críticos.

Palavras-chave: Ensino Superior e Saberes Científicos. Educação Básica e Epistemologia da Prática. Formação de Leitores.

\footnotetext{
* Doutora em Letras pela Universidade Estadual Paulista Júlio de Mesquita Filho (UNESP), Campus Assis. Professora do Departamento de Educação da Universidade Estadual Paulista Júlio de Mesquita Filho (UNESP).
} 


\section{Introdução}

Como destaca Kristeva (1974), apoiada na abordagem histórico-cultural bakhtiniana, a leitura, na concepção semiótica da Intertextualidade, constitui um ato complexo de reconstrução da escrita, que pressupõe a sintonização cultural do leitor com o autor, identificando, necessariamente, a situação de origem sociocultural do texto. Considerando-se autor e leitor como entidades históricas, situadas num tempo e espaço determinados, com repertórios culturais específicos, pode-se avaliar a complexidade (profundidade) das relações de sentidos estabelecidas na rede de signos de um texto. Na apreensão desses sentidos (literais e situacionais) que emergem do texto, perpassam relações culturais (BAKHTIN, 2014) ${ }^{1}$ dos interlocutores (usuários dos signos), revelando o repertório enciclopédico (ECO, 1980, 1991) dos atores sociais envolvidos no processo de leitura.

Diversas são as contribuições no Brasil que vêm destacando, para maior eficácia das práticas escolares, a importância do conhecimento docente sobre essa complexidade semiótica do processo de leitura, para não ocorrência de inadequações metodológicas no seu ensino; dentre esses estudos, lembramos: CHIAPPINI (1998); KLEIMAN (1989); SOARES (2004); SILVA (2003); MARCUSCHI (2008); DEL RÉ (2009); BRITO (2010); KOCH (2005, 2010); GROSSI , GEROLDO e BAFFA (2011); KOCH, BENTES e CAVALCANTE (2012); OLIVEIRA (2013); SMOLKA e NOGUEIRA (2013); DEL RÉ, PAULA e MENDONÇA (2014); e outros.

Retomando as reflexões teóricas semióticas sobre o texto, o signo e a significação, enfatizamos que o leitor é um (co) produtor dos sentidos estabelecidos no texto pelo autor e que ambos, seres sociais, de forma dialógica, se constroem e são construídos na e pela linguagem do texto. No entanto, os formadores de leitores da Educação Básica estariam compreendendo a leitura como essa atividade sociocomunicativa de produção de sentidos conjuntos, pautados na interação social dos usuários dos signos (autor e leitor)? Teriam os profissionais desse nível de escolarização um "patrimônio de saber" (ECO, 1980, p. 125) significativo, herdado dos cursos de graduação por eles realizados, para um ensino crítico da leitura, que pressupõe, necessariamente, o reconhecimento da natureza ideológica (discursiva) dos signos, declarada por Bakhtin (2014), Kristeva (1974), Eco (1980, 1991), Chartier (1990), Vigotski (1972, 2005) e outros estudiosos?

A nosso ver, pesquisar o perfil do professor da Educação Básica, sua formação inicial e continuada, pode resultar dados contributivos para um ensino mais eficaz da leitura, já que a pesquisa em Educação deve abranger a dinâmica global da ação docente, permeando a história de formação dos 
professores, suas representações de leitura, os sentidos sociais do seu trabalho e suas práticas tradutoras das políticas institucionais de formação de formadores de receptores críticos de textos.

Tal conteúdo gerou o interesse pelo desenvolvimento da pesquisa $A$ formação do formador de leitores nos cursos de letras e pedagogia (TREVIZAN, 2013 - 2015) ${ }^{2}$, de cujos dados resultou o presente artigo. Pela metodologia qualitativa (ANDRÉ, 2008), este estudo, de aporte teórico históricocultural, teve como objetivo repensar o processo de formação teórico-cientifica e prática do professor da Educação Básica, configurado no cotidiano da formação inicial superior (graduações em Letras e Pedagogia) e nas suas vivências profissionais e sociais continuadas. Participaram da pesquisa duas egressas desses cursos, ofertados por Instituições Particulares, atuantes em uma escola do interior do estado paulista (Município de Presidente Epitácio - SP). A coleta dos dados foi efetuada por meio de entrevista semiestruturada, com aplicação de questionário e realização de três encontros para reflexão e tematização das respostas obtidas das docentes participantes.

A escolha da metodologia qualitativa (estudo de caso) ocorreu em razão da intenção de unir uma investigação "de caso" com a análise do contexto histórico de formação das participantes da pesquisa. Como afirma André (2008, p. 16-17), referindo-se aos estudos de Merrian (1988), o conhecimento gerado pelo estudo de caso é "mais concreto", "mais contextualizado", "mais voltado para a interpretação do leitor" e "baseado em populações de referência determinada pelo leitor”. Assim, a realização da pesquisa aproximou a pesquisadora da situação e das profissionais pesquisadas, tornando a experiência mais viva do que a que ocorre em outras modalidades de estudo; possibilitoulhe que, nos encontros de reflexão e tematização dos dados, fizesse o acréscimo de suas próprias experiências (teóricas e práticas) em ensino de leitura; permitiu-lhe estender a generalização das reflexões para outros interessados no assunto.

\section{Formação docente e formação de leitores}

Pimenta e Anastasiou (2014, p. 49), ressaltam que, já no período de 1996 a 2000, pesquisadores brasileiros vêm constatando uma nova concepção de ensino como um "fenômeno complexo", direcionado pela necessidade de uma formação docente, focada na perspectiva denominada “epistemologia da prática" que "investiga o ensino em situação", ou seja, investiga-o de forma sociopragmática, o que demanda saberes científicos do professor e sua capacidade crítica de autorreflexão e tematização da sua prática, a partir de conhecimentos plurais das teorias da 
complexidade e da interdisciplinaridade, da filosofia materialista da linguagem, da psicolinguística/sociolinguística, da psicologia social, da cultura escolar, das políticas públicas e de outras.

A contribuição de Chartier (1990), dentre outros estudiosos, nos dá suporte para compreendermos que os conceitos do trabalho docente, implícitos na linguagem emitida pelos próprios profissionais, nos permitem identificar o passado histórico-cultural das representações que constituíram a construção do seu repertório de saberes e que retroalimentam o seu discurso e a sua prática pedagógica do presente. Esse autor alerta sobre o papel sociocultural dos professores na orientação da leitura, que exige deles a própria condição crítica de reflexão sobre suas maneiras de ler, para um procedimento pedagógico adequado, nos processos de formação da competência leitora de seus alunos.

É fundamental que os docentes formadores de leitores também conheçam o que Bakhtin (2003, 2014) e Vigotski (1972, 2005) destacam sobre a relevância da perspectiva teórica de concepção histórica e social da linguagem, como fator determinante da integração do indivíduo à cultura. Para os autores citados, é por meio da linguagem que as relações contextualizadas de significados se estabelecem e se sedimentam, culturalmente, nos processos sociais de construção dos repertórios enciclopédicos dos seres humanos, em constante formação. Segundo eles, sendo a subjetividade impregnada das relações estabelecidas por um sujeito histórico, situado em um determinado tempo e em um determinado espaço, as interações sociais são determinantes na construção do saber de cada indivíduo e na formação da sua identidade. Em outros termos, as funções psíquicas e as práticas humanas, segundo a concepção bakhtiniana e vigotskiana, se originam de processos sociais plurais, complexos, pautados no dinamismo e na multiplicidade das esferas da experiência humana - cultural, escolar, religiosa, política, econômica, científica, tecnológica, midiática...

Transferindo as reflexões teóricas de Chartier, Bakhtin e Vigotski para o campo da Educação, afirmamos que o significado do trabalho do professor também traz marcas desse contexto histórico e cultural da sua formação institucional e dos seus percursos de vida.

Vaillant e Marcelo (2012, p. 199) informam que "proliferam os informes e estudos com abundante evidência sobre os programas de formação inicial e contínua de docentes", mas ressaltam a “dissociação" desses programas em relação à sociedade da informação, geradora de uma "realidade educativa em contínua mudança". Enfatizam esses autores (2012, p. 200) que "o conhecimento não pode ser compreendido à margem do contexto no qual surge e ao qual se aplica". Assim, após sugerirem experiências formativas mais adequadas ao contexto da Educação no século XXI (focadas na 
"aprendizagem cooperativa"; fomentadas pela "interação e intercâmbio de ideias e materiais" entre docentes e estudantes; e centradas no "conhecimento distribuído", entre indivíduos, grupos e ambientes), Vaillant e Marcelo (2012, p. 201) indagam: “O que devem aprender e como deveriam aprender os futuros docentes?"

Refletindo sobre essas questões colocadas por Vaillant e Marcelo, destacamos que todo indivíduo é produto de uma interação social coletiva, como explicitam as teorias socioculturais; e, se falta aos docentes uma epistemologia crítico-dialética da própria prática, a ponto de, muitas vezes, não conseguirem identificar, no cotidiano da profissão, os pressupostos teórico-científicos herdados das graduações cursadas (que originaram suas crenças, conceitos, representações e práticas) o que se impõe, dentre outras possibilidades de melhoria da formação docente, é estabelecer, nos cursos de graduação, uma maior atenção à construção do "conhecimento padronizado" e "especializado" do professor (IMBERNÓN, 2010, p. 31). É clara a necessidade de, na formação acadêmica, o graduando apropriar-se do conhecimento pedagógico "padronizado" (conceitos teóricos registrados no patrimônio cultural da sua área de conhecimento) para, na prática futura, saber explorar o conhecimento pedagógico “especializado", que é o conhecimento unido à sua ação docente.

Então, o que e como devem aprender os atuais e os futuros docentes, para o trabalho específico de formação de leitores? É imprescindível que os professores saibam o que é texto! O que é linguagem! O que é signo! O que é significação! O que é leitura! Mas é importante que esses conceitos lhes sejam apresentados por meio de teorias que valorizem o ato de ler como um processo socioideológico. Nesse sentido, os estudos histórico-culturais são contributivos, pois enfatizam a inexistência da neutralidade da linguagem, e, na prática da sala de aula, de forma interativa, podem servir de sustentação teórica na definição da função social das atividades/ações propostas para leitura de textos. Pela abordagem histórico-cultural, a formação do formador de leitores implica um diálogo de conhecimentos: 1. os conhecimentos teórico-científicos de conceituação dos textos verbais e visuais, considerados, nessa perspectiva teórica, como produtos discursivos e, portanto, como processos sociopragmáticos de comunicação humana; e 2. os saberes criativos do professor para (com base nos conhecimentos teóricocientíficos) planejar atividades/ações adequadas às situações concretas, reais, do ensino e da aprendizagem.

Mas o profissional formador de leitores, graduado em Letras e Pedagogia, atuante na Educação Básica, apresenta essa complexidade de conhecimentos para construção de uma "epistemologia da prática" (PIMENTA; ANASTASIOU, 2014, p. 49) que lhe permita uma continuada investigação do 
seu próprio ensino, situado histórico-culturalmente? O repertório cultural desse profissional (formador de leitores) o habilita para o desafio de ensinar os alunos a pensarem e a reconhecerem as marcas culturais implícitas na linguagem (estratégica) dos autores dos textos (ou seja, a reconhecerem os sentidos situacionais dos discursos), ou apenas o predispõe a conduzir os alunos à identificação única dos sentidos literais explícitos no conteúdo dos textos?

Imbernón (2010, p. 51) afirma que um novo conceito de formação, no contexto atual da Educação, deve prever o desenvolvimento da capacidade de o professor "descobrir, organizar, fundamentar, revisar e construir a teoria”. Concordamos com o autor; no entanto, no Brasil, a realidade cultural das Instituições de Educação Básica é outra. Como os profissionais desse nível de ensino construirão teorias (ou pelo menos as revisarão, as fundamentarão), se ainda pode faltar, na formação docente, o alicerce teórico-científico para o exercício cotidiano de autoavaliação e reconstrução continuadas das próprias práticas e, até mesmo, para uma identificação dos pressupostos teóricos que norteiam atividades/ações inseridas em materiais didáticos de ensino de leitura que lhes são repassados pelo Estado? É o que ocorre em programas e projetos paulistas; por exemplo, nos Cadernos do professor e do aluno (2014) do São Paulo Faz Escola; nas Coletâneas de Atividades (2010) do Ler e Escrever e nas propostas contidas no Programa Sala de Leitura em escolas de ensino integral (2009), que vêm constituindo objetos de reflexões, discussões e orientações, vivenciadas nas nossas próprias práticas acadêmicas, de ensino, pesquisa e extensão, que podem servir, aqui, de breve ilustração da problemática apontada.

Trevizan (2015) afirma que - embora o Currículo do Estado de São Paulo: Língua Portuguesa (SÃO PAULO, 2010) constitua um documento de aporte teórico histórico-cultural (de origem bakhtiniana e também vigotskiana) anunciando, portanto, a relevância das práticas dialógicas, sociopragmáticas de leitura - nos Cadernos do Professor e dos Alunos (2014), gerados do Currículo (2010) e acoplados ao projeto São Paulo Faz Escola, as atividades discentes propostas se limitam a exercícios redutores do ato de ler, como um ato individual, descontextualizado e, portanto, não compartilhado socialmente. Nesses Cadernos, a fundamentação teórica histórico-cultural, anunciada no Currículo, não é materializada nos modelos de atividades discentes de leitura; por exemplo, diversos gêneros textuais são sugeridos para uma leitura intertextual; mas essa intertextualidade só ocorre centrada em uma identificação temático-conteudística dos modelos textuais, e não na compreensão do discurso (texto em contexto), ou seja, na compreensão das interações culturais e interdiscursivas que a 
linguagem do texto estabelece com o próprio autor, com o leitor e com os outros textos produzidos em momentos anteriores ou simultâneos à sua produção.

As considerações críticas sobre os Cadernos do projeto São Paulo Faz Escola (TREVIZAN, 2015) e também sobre a Coletânea de Atividades no Ler e Escrever, (PARISOTTO; TREVIZAN, 2012) destacam que a leitura do texto literário, que deveria assumir virtualidades múltiplas, canalizadas em direção ao criador (SUJEITO histórico) e, a partir dele, em direção à SITUAÇÃO da origem discursiva, acaba sendo limitada a uma leitura meramente conteudística, inviabilizando, inclusive, a produtividade do processo da mediação docente no ensino da literatura. No mundo contemporâneo, em que predomina a obviedade das linguagens pragmáticas, é fundamental que o leitor de literatura ultrapasse a previsibilidade (literalidade) dos sentidos extraídos do código linguístico (utilizado no texto) e alcance a imprevisibilidade do movimento das nuances significativas (filosóficas, ideológicas e culturais) que emergem da SITUAÇÃO de origem do texto. No caso da leitura dos textos literários, de natureza artística, cumpre lembrarmos que essa priorização, nos procedimentos metodológicos, da exploração de uma leitura literal dos conteúdos temáticos, só pode resultar no desconhecimento continuado dos leitores (em formação) sobre os fundamentos filosóficos e culturais da Estética e da Filosofia, contidos na Arte; fundamentos essenciais à formação da identidade humana.

Também o Programa Sala de Leitura do Estado Paulista (2009) foi tema gerador de uma dissertação de mestrado de Ferreira (2016), sob nossa orientação, intitulada O perfil do professor como responsável pelo "Programa Sala de Leitura” em escolas públicas de uma cidade do oeste paulista: formação docente e práticas de mediação, que teve o objetivo de identificar e discutir a formação docente (inicial e continuada) de três profissionais responsáveis pelo Programa e as suas práticas de mediação no processo de construção do pensamento crítico-reflexivo dos alunos/leitores. Os resultados obtidos dessa pesquisa permitiram uma valorização do empenho e dos investimentos do estado paulista na criação e implementação desse Programa, que fomentou um discurso de encantamento das três docentes envolvidas, porém impôs, ao mesmo tempo, a necessidade de o pesquisador transformar esse discurso do encantamento em objeto de reflexão crítica no corpo da dissertação, já que esse Programa possibilita, positivamente, forte estimulação para o acesso do aluno a diferentes materiais de leitura (livros, revistas, jornais), mas, nos modos de ensino da leitura, conduz o docente à permanência de abordagens limitadas ao conteúdo dos textos, não se valorizando a leitura da linguagem (e de seus recursos expressivos, estratégicos), para estabelecimento do diálogo do(s) leitor(es) com o autor e com o contexto situacional dos discursos. Tal procedimento atenua a relevância cultural do trabalho da 
mediação docente. Apesar de valorizar ações gerais de intensa motivação para inserção dos alunos em espaços de convivência com os materiais de leitura (escola, família, feiras culturais), o Programa não coloca em prática os modos críticos de como se deve efetuar uma leitura pragmática dos recursos expressivos das linguagens (dos textos lidos), enquanto veículos ideológicos dos conteúdos identificados.

É frequente, ainda, encontrarmos as mesmas inadequações metodológicas de ensino da leitura, nos livros didáticos (da Educação Básica), identificadas em dissertações de mestrado (sob nossa orientação) que geraram publicações posteriores de artigos. Citemos, apenas para ilustração dessa problemática, duas experiências mais recentes: Docência e pesquisa na educação básica: a importância da análise documental de livros didáticos (TREVIZAN; SAMPAIO, 2014); e O discurso fotográfico no livro didático: representações e práticas inadequadas de leitura (TREVIZAN; LOPES; SOUZA, 2016). Os resultados obtidos desses estudos confirmaram a continuidade, no tempo, das inadequações metodológicas ocorridas no ensino da leitura de textos, já designadas por Chiappini (em 1988) como resultado de uma desistoricização da linguagem, gerando consequências óbvias nas práticas docentes e nos processos de formação crítico-ideológica dos leitores. Ambos os artigos informam que o aporte teórico anunciado pelos autores didáticos (de perfil histórico-cultural) não se materializou na elaboração das atividades discentes, propostas para a compreensão dos textos verbais e visuais. No caso das especificidades da leitura da linguagem visual, as atividades discentes determinam, pela superficialidade da sua natureza, uma mera descrição dos dados vistos/observados pelo receptor e não conduzem o leitor ao diálogo cultural do texto com uma situação real, social (de comunicação visual). É estimulada tão somente a imaginação do leitor, mas as relações sociais, ideológicas, filosóficas, implícitas na linguagem visual, são neutralizadas, não possibilitando ao docente (usuário desses materiais) o exercício da sua condição de "Agente Cultural” (SILVA, 2003, p. 51), na mediação do processo de formação de leitores.

Pautando-nos na complexidade dessa problemática apontada, lembramos a necessidade de uma revisão do espaço de atuação profissional dos professores do Ensino Superior nos processos formativos dos formadores de leitores da Educação Básica, de modo a prepará-los como agentes culturais/mediadores no ensino da leitura. É claro que, no que concerne à qualificação do profissional da Educação Básica, não cabe uma atribuição única à Universidade para a transformação cultural desejada. É evidente a integração necessária entre formação teórica e formação prática, como uma responsabilidade não só da Universidade, mas também como um comprometimento maior dos Estados 
e Municípios, que precisam rever e retroalimentar as suas modalidades de formação, de modo a possibilitar ao professor a própria condição de leitor crítico dos materiais com os quais trabalha.

Ainda em relação à formação docente, precisamos de precaução, diante de algumas falas, como, por exemplo, a de que a atualização teórica acadêmico-científica do professor constitui um conceito obsoleto de formação continuada, devendo-se, consequentemente, privilegiar a criatividade e a invenção. A nosso ver, uma formação teórica histórico-cultural do professor é bastante contributiva para o alcance intelectual de construção de uma epistemologia da própria prática, pela qual se faça avaliador do que e de como ensina. Ninguém cria ou recria teorias, a partir do nada. Vigotski (1972) vê a própria Arte como um produto social e não como um ato inteiramente inaugural, resultante da criatividade do autor. De igual forma, o professor só alcança a condição intelectual de rever, contestar, recriar, criar teorias, a partir de um "patrimônio de saber" (ECO, 1980, p. 125) que o habilite a formar uma postura investigativa, de utilização de sua própria prática como objeto de reflexão epistemológica para revisão/atualização/transformação da mesma.

Como privilegiar, na prática docente, caminhos metodológicos inovadores, sem uma competência intelectual e intertextual, produzida no próprio ato de compartilhamento do professor leitor com os autores dos textos (teórico-científicos) lidos? A questão da gênese das competências profissionais do professor é bastante complexa, porque sua configuração só emerge, se pautada na formação teórica, nas práticas e nas vivências sociais, construídas historicamente. Não há como separar o particular do social; o individual do histórico-social.

Não é por acaso que, na Educação, no Brasil, predominou um modelo de ensino tecnicista, empírico, durante os anos do período ditatorial (1964-1984), embora ocorresse, sobretudo a partir dos anos 70, também a convivência com outros modelos educacionais emancipatórios, como o Cognitivista Interacionista Piagetiano e o Cognitivista Sociointeracionista Vigotskiano. Estudos acadêmicos (CASTORINA; LERNE; OLIVEIRA, 1996; FREITAS, 2004; DEL RÉ, 2009) informam a evolução histórica do empirismo para o racionalismo e para o interacionismo social, na Educação Brasileira, focando estudos sobre linguagem e contribuindo, assim, para reflexões e transformações do pensamento escolar sobre práticas de formação de leitores.

Nessa linha evolutiva de conceitos teóricos e de modelos pedagógicos de ensino de leitura, se faz, também, fundamental lembrarmos os pressupostos teóricos da Linguística Clássica de Ferdinand de Saussure, baseados na sua obra fundamental Curso de linguística geral (1.ed., 1916), utilizada, na sua vigésima sexta edição, de 1922, por Bakhtin (2014, p. 87, nota 22), como objeto de crítica 
contundente à sua teoria linguística descritiva (sincrônica) que, em contraste com a linguística histórica diacrônica, separa a LÍNGUA da FALA, privilegiando a primeira como objeto único de estudo e desconsidera a LINGUAGEM, em razão da sua natureza compósita e dialógica (LÍNGUA x FALA). $\mathrm{Na}$ concepção saussuriana, o signo linguístico envolve a relação restrita entre o significante (massa corpórea do signo) e o significado (conteúdo nocional, abstrato), desvalorizando os aspectos sociopragmáticos (da FALA) que determinam os sentidos situacionais dos signos. Tal conceito redutor de signo e de significação acabou gerando um modelo de leitura pautado na identificação, pelo leitor, das relações (gramaticais) dos signos entre si, firmadas no tecido textual (fechado em si mesmo). Assim, com base nessa concepção, os aspectos semânticos do texto são identificados, nos atos de leitura, pelo uso/domínio individual (do leitor) dos sentidos (literais) do dicionário da LíNGUA na qual foi produzido o texto.

Com a divulgação, no Brasil, das teorias histórico-culturais (VIGOTSKI; BAKHTIN; LURIA; LFONTIEV e TODOROV), sobretudo nos anos 70 e posteriores, começa uma evolução da teoria LINGUÍSTICA CLÁSSICA SAUSSURIANA para a teoria da LINGUÍSTICA TEXTUAL, acrescentando-se uma percepção mais abrangente do ato de ler, compreendido, então, como um ato de LINGUAGEM (processo social de compartilhamento cultural) que exige a sintonização do SUJEITO leitor com o SUJEITO autor (seres contextualizados) e a identificação das relações de sentidos pragmáticos que emergem da SITUAÇÃO externa, de origem do texto.

Segundo Reis e Lopes (1988, p. 27-9), já nos anos 60, a obra de Benveniste, Problemas de linguística geral, na sua primeira edição (1967) abriu "novos horizontes aos estudos linguísticos pela introdução do sujeito e da situação como parâmetros decisivos na descrição da atividade verbal"; tais parâmetros de ordem ideológica e sociocultural, destacados por Benveniste (1976), foram sendo ressaltados por outros estudiosos, tal como Pêcheux (1988), endossando a definição bakhtiniana (2014) de LINGUAGEM como uma "síntese dialética" da LÍNGUA e da FALA. Diferentemente de Saussure, que prioriza a LÍNGUA e desconsidera a LINGUAGEM, Bakhtin elege a LINGUAGEM, na sua natureza compósita e indissociável (LÍNGUA x FALA), como objeto central de suas investigações. Para o autor da Filosofia Materialista da Linguagem, a "língua vive e evolui historicamente na comunicação verbal concreta, não no sistema linguístico abstrato das formas da língua nem no psiquismo individual dos falantes" (2014, p. 128). O "subjetivismo idealista" da FALA (ato individual, subjetivo de uso da língua) e o "objetivismo abstrato" da LíNGUA (sistema de normas linguísticas, produto social coletivo) constituem a "síntese dialética" do conceito bakhtiniano de LINGUAGEM 
(2014, p. 126). Para ele, o "grau de consciência, de clareza, de acabamento formal da atividade mental é diretamente proporcional ao seu grau de orientação social” (2014, p. 118); em outros termos, as relações dialógicas e ambivalentes da "atividade mental do eu" e da "atividade mental do nós" constituem a base concreta da materialização do processo de compreensão do homem. Bakhtin, portanto, não exclui a corrente teórica do "objetivismo abstrato" (centrada no estudo da língua, como propõe Saussure), mas a inclui no diálogo necessário com a teoria do "subjetivismo idealista" (de valorização do ato individual da fala), para a proposição final de uma "síntese dialética", definidora do seu conceito de linguagem.

Assim, embora os dados obtidos do estudo, que será relatado na sequência desse artigo, constituam apenas uma amostragem de uma problemática a ser mais investigada, as falas das docentes entrevistadas são representativas de uma formação acadêmica pautada na teoria clássica saussuriana, de valorização dos sentidos literais dos conteúdos do texto, em detrimento de uma abordagem dos seus sentidos situacionais; as docentes informaram, em suas falas, não terem recebido, ao longo de suas formações (uma delas graduada em Letras em 1988; e a outra, em Pedagogia em 2005) nenhum aporte teórico de perfil sociointeracionista/histórico-cultural.

É lamentável esse desconhecimento docente das teorias histórico-culturais, porque suas contribuições conceituais são importantes para a formação crítico-reflexiva dos professores, já que elas estabeleceram um novo paradigma na Educação, aproximando-a dos estudos da Psicologia Social. Tal aproximação valoriza a natureza processual e dialética da linguagem. A leitura, no aporte teórico da semiótica bakhtiniana e vigotskiana, é considerada como uma produção cultural, equacionada em termos sociossemióticos, e o desconhecimento teórico do docente de valorização do contexto na leitura final do texto pode comprometer a função mediadora do professor, ator relevante no processo das interações verbais estabelecidas a partir do texto. A ausência de professores mediadores no ensino da leitura pode desencadear entraves no processo de ensino-aprendizagem da leitura, pois, no ato de ler, o leitor e o autor, enquanto seres sociais, interagem entre si e ambos dialogam com o texto (objeto), que se vincula a uma dada situação, a qual participa, igualmente, da determinação dos sentidos a serem apreendidos pelo receptor. E, nesse movimento dialético da leitura, o leitor se edifica como um ser social, pensante, crítico-reflexivo.

A nosso ver, o conhecimento dos referenciais histórico-culturais de Bakhtin, Vigotski, Chartier e outros é fundamental para a construção cultural de um professor (leitor) consciente, crítico-reflexivo, apto a usar os seus conhecimentos e a sua criatividade nos processos pedagógicos de formação de 
leitores. Para Xavier (2014, p.831), as “microdecisões tomadas na sala de aula” são reveladoras da potencialidade pessoal, crítica, reflexiva, emancipatória do profissional docente e emergem, obviamente, das "trajetórias sociais" vivenciadas por ele; e, relembrando o ponto de vista de Nóvoa (1987), Xavier (2014, p. 831) ainda completa afirmando que a formação docente não pode ser constituída apenas de um aprendizado prático, mas deve pautar-se em um referencial teórico reconhecido em um "quadro acadêmico, institucionalizado".

\section{A formação do formador de leitores nos cursos de Pedagogia e Letras}

Os professores da Educação Básica, para exercerem suas condições de leitores críticos da sua própria identidade e prática profissional, precisam ter consciência dos significados culturais de origem dos seus conceitos, representações e práticas de ensino de leitura, herdados dos cursos de graduação e do seu cotidiano escolar.

Segundo Brito (2010, p. 242), “os graduandos formam crenças sobre si próprios e suas capacidades, sobre a natureza do conhecimento e sobre como o conhecimento é adquirido ou aprendido. Essas crenças geralmente são inconscientes”. As falas das profissionais participantes (P1 e P2) da pesquisa realizada (TREVIZAN, 2013, 2015) também revelaram crenças herdadas das graduações que, como enfatizou Brito (2010, p. 242), fazem parte de uma "memória discursiva", gerada de um "saber discursivo" da própria formação escolar. E, segundo essas professoras entrevistadas, esse saber convencionalizado é repassado academicamente e difícil de ser transformado, na prática, pelo professor. Xavier (2014, p. 832-833) expõe que, na teoria sociológica de Dubar (2005), as identidades são "construções históricas - sociais e de linguagem - e, como tal, são acompanhadas por racionalizações e reinterpretações que às vezes se fazem passar por essências intemporais". As falas das professoras (P1 e P2) confirmam, pois, essa natureza intemporal do conhecimento herdado culturalmente, que atravessa o tempo, em razão, também, da acomodação ou da falta de oportunidades culturais de quem o recebe.

Os dados da pesquisa revelaram que as duas professoras (a P1, graduada em Pedagogia em 2005; e a P2, graduada em Letras em 1988) usam, nas suas práticas, nos anos dois mil, um conceito de leitura restrito a uma fundamentação de embasamento teórico-linguístico (clássico), herdado dos estudos de Ferdinand de Saussure. As professoras afirmaram que ainda não têm repertório cultural teórico suficiente à efetuação de uma avaliação crítica para transformação ou recriação do que fazem 
em sala de aula. De fato, nenhuma delas, ao longo da profissionalização (P1, 30 anos) e P2 (25 anos), efetuou reinterpretações dessas formações culturais identitárias, fazendo-as, de fato, permanecerem como "essências intemporais" (XAVIER, 2014, p. 833).

Passemos à descrição analítica desse "saber discursivo" da escola (BRITO, 2010, p. 242), explicitado nas falas das duas participantes da pesquisa. As respostas ao questionário escrito (utilizado na entrevista) foram debatidas com as docentes em três encontros e resultaram na organização de vários conteúdos temáticos, dos quais extraímos alguns para discussão nesse artigo.

Na identificação do perfil das participantes, observamos uma longa experiência profissional (de 30 e 25 anos). No entanto, a P2, graduada em Letras em 1988, ao longo de sua atuação profissional (25 anos), frequentou uma Oficina e um Curso de Extensão, ambos de curta duração, não tendo, inclusive, alcançado a aprovação em Concurso Público de efetivação. Informou experiência em coordenação pedagógica. A fala dessa participante é reveladora da importância dada por ela à parte prática; não destaca, por exemplo, as consequências advindas de uma descontinuidade da sua formação teóricocientífica iniciada no Ensino Superior e interrompida ao longo dos anos do exercício profissional. Também a P1, graduada em Pedagogia em 2005, embora já tenha 30 anos de exercício profissional docente, apresentou, após a graduação cursada, o mesmo distanciamento da Universidade que a P2; ambas não participaram de eventos de formação promovidos por Universidades e de outras iniciativas dessa natureza ou de projetos acadêmicos. Cumpre destacarmos que, embora P1 tenha se graduado em 2005 e, apesar de ter sido efetivada por Concurso Público, revelou (como P2) a mesma formação teórica linguística (de base saussuriana) para ensino da leitura.

$\mathrm{Na}$ identificação das experiências em metodologias específicas de ensino de leitura, vivenciadas durante a formação nas graduações, constatamos o desconhecimento das duas profissionais sobre Metodologias do Ensino: de Leitura; de Língua Portuguesa; de Literatura Infantil; de Linguagens Visuais e de Artes.

Sabemos que uma metodologia de ensino de leitura pressupõe o processo de uma organização conceitual (de natureza epistemológica e político-social) e de uma organização formal (de construção da sequência lógica das atividades) a serem trabalhadas com os alunos, a partir de conceitos e representações sociais definidos previamente, no ato da organização conceitual do trabalho. Tendo em vista o exposto, o que esperar da prática docente de professores que, nas graduações, não cursaram nenhuma disciplina de metodologia vinculada ao ensino da leitura? É esperado que, não tendo conhecimentos e experiências em metodologias específicas de ensino de leitura (de diferentes 
linguagens), o docente apenas siga as atividades discentes propostas nos materiais didáticos adotados (livros didáticos, cadernos do professor) como uma mera sequência de passos a serem executados, sem a consciência crítica da necessidade de saber identificar os conceitos e as representações de leitura que fundamentaram as atividades discentes. Nos encontros da pesquisadora com as duas docentes participantes (para discussão e tematização dos dados da pesquisa), ambas afirmaram e lamentaram ter uma formação teórica precária, que não lhes possibilita uma identificação das teorias científicas que norteiam os modos de ensino propostos nos materiais didáticos utilizados pela Escola em que atuam.

$\mathrm{O}$ que precisa ser refletido mais amplamente é a quem interessa um profissional docente (formador de leitores) sem a consciência crítica da imposição de um ensino neutralizante do próprio papel mediador do professor (um ser cultural em constante transformação) e de uma equivalente neutralização dos efeitos sociais da linguagem e do tipo de ensino ministrado.

Investigando a identificação das teorias de suporte para abordagens metodológicas dos textos (estudadas nos cursos de graduação), obtivemos a declaração das duas entrevistadas sobre o desconhecimento total das teorias materialistas da linguagem (teorias semióticas, de Bakhtin, Vigotski e outros). As duas profissionais informaram, nas respostas ao questionário aplicado, terem adquirido conhecimento, nas graduações obtidas (Pedagogia e Letras), apenas da Teoria Linguística de Ferdinand de Saussure; revelaram desconhecimento da complementação da Linguística Clássica Saussuriana, pela Linguística Textual, centrada no estudo da linguagem, que concebe o texto como um discurso, equacionado sociossemioticamente por elementos linguísticos e por elementos extralinguísticos, dos quais participam os SUJEITOS, usuários dos signos, e as SITUAÇÕES de contextualização dos sentidos pragmáticos do discurso. Suas falas, registradas nos Dados da Pesquisa em 2014, são confirmadoras de uma formação teórica precária sobre a abordagem de textos: "No ensino de leitura, a abordagem textual era sempre de forma bem superficial, considerando apenas informações explícitas." (Fala da P1). E ainda: "A leitura era abordada no sentido explícito apenas complemento da gramática, dando ênfase somente no que era mecânico para o funcionamento da língua.” (Fala da P2).

Essa formação teórica insuficiente, herdada das graduações realizadas pelas docentes entrevistadas, fica ainda mais clara na discussão dos dados referentes aos conceitos e aos exercícios de leitura incorporados nos seus repertórios culturais. Ambas revelaram desconhecimento teórico do conceito de leitura como um ato de natureza sociossemiótica e também o desconhecimento do conceito de leitura estética de textos artísticos (como contos, poesias, filmes e outros discursos visuais). Ainda 
foi ressaltado, por elas, o desconhecimento dos conceitos teóricos de diferenciação da natureza dos textos literários e dos não literários.

Assim, os conceitos inadequados de leitura, herdados pelas participantes da pesquisa, acabaram determinando, nas práticas profissionais do ato de ler, a busca única dos sentidos (de dicionário) das palavras do texto verbal escrito e um retorno imediato ao texto lido, para mera compreensão linguística de parágrafos e frases. Também os exercícios de leitura estética das linguagens artísticas (verbais e visuais) nunca ocorreram no período de realização dos cursos de graduação de ambas as docentes, gerando lamentação das profissionais, em relação à própria formação em nível superior:

Como transmitir aos alunos conhecimentos que o professor não recebeu durante a sua formação universitária se nem sequer o material destinado a dar suporte pedagógico na organização metodológica de suas aulas, traz essa abordagem para orientá-lo?

FALA da P1 (Graduada em Pedagogia, em 2005)

FONTE: Dados da Pesquisa, 2014.

Os estudos eram baseados somente em um objetivo solto, não davam oportunidade de conhecer o conceito e suas tipologias textuais claramente.

FALA da P2 (Graduada em Letras, em 1988)

FONTE: Dados da Pesquisa, 2014.

Percebemos, nos discursos transcritos, que faltam saberes teórico-científicos capazes de dar às professoras suporte à necessária organização metodológica de suas aulas de leitura. Acrescentam que os materiais didáticos, utilizados pela Escola para apoio pedagógico ao docente, também não explicitam os pressupostos teóricos que norteiam as Atividades Discentes. Pelas falas citadas, deduzimos que o professor acaba se submetendo, consequentemente, a um uso acrítico do material.

Como afirma Dubar (2005, p. 37), “a formação intervém nas dinâmicas identitárias muito para além do período escolar”. De fato, mesmo após anos de conclusão das graduações, os conceitos recentes das duas professoras sobre TEXTO permanecem limitados, em razão da não valorização da natureza socioideológica do discurso. Para P1, o texto é um "conjunto de palavras e frases falada ou escrita sobre um determinado assunto"; e, para P2, o texto é "uma ocorrência linguística escrita ou falada de qualquer extensão.” (FONTE: Dados da Pesquisa, 2013-2015). As duas professoras não revelaram, nessas falas, conhecimento da dimensão de uma realidade sociopragmática determinante dos sentidos culturais do texto, pois o definiram somente como uma "ocorrência linguística" (P2) ou “conjunto de palavras e frases" (P1). Tais limitações conceituais de texto se justificam, diante do desconhecimento (revelado por elas) da LINGUÍSTICA TEXTUAL que enfatiza a natureza discursiva do texto. 
Causou surpresa, portanto, que as docentes, ao exporem seus conceitos de LEITURA, deixaram transparecer o reconhecimento de que a leitura dos sentidos literais do texto não é suficiente para uma decodificação completa do mesmo; ressaltaram a importância do "contexto de produções" como fator determinante da leitura (P1) ou, como ocorreu na fala de P2, foi insinuado que ler não é simplesmente “decodificação de símbolos”, mas, sim, implica o ato interpretativo, para se compreender o que se lê. No entanto, sobre isso, as professoras esclareceram, em suas afirmações posteriores, que esse acréscimo teórico de que, na leitura, deve prevalecer a descoberta dos sentidos não só explícitos no texto (mas também implícitos no contexto) apenas ocorreu ao longo dos anos, por meio de esporádicas e insuficientes oficinas, capacitações e cursos de extensão:

Só após os cursos de extensão cultural e participação em oficinas culturais oferecidas pela D.E. é que começamos a ter uma leve e superficial ideia sobre o assunto. Ainda temos muito a aprender.

[...] os treinamentos oferecidos são bem superficiais (pouco tempo, conteúdo extenso e complexo) sempre durante o percurso de atuação. Gera angústias, sofrimentos e muitas decepções.

FALA da P1 (Graduada em Pedagogia, em 2005)

FONTE: Dados da Pesquisa, 2014.

A partir dos treinamentos, cursos de atualização, [...] esses conceitos foram adquiridos após a graduação e foram se aperfeiçoando ao longo dos anos, principalmente na prática ora acertando, ora errando [...]

FALA da P2 (Graduada em Letras, em 1988)

FONTE: Dados da Pesquisa, 2014.

As falas transcritas acima são confirmadoras do que Hypolito (1997, p. 97) considera “aligeiramento da formação docente”, feito, geralmente, por Estados e Municípios. Torna-se necessária uma revisão dessa modalidade de formação esporádica, fragmentada, que apesar de surtir efeitos de “alerta" aos docentes, acaba causando, nos mesmos, muito mais ansiedade, em razão de uma frágil conscientização da sua carência de saberes científicos e do não saber fazer, do que a satisfação de obter caminhos de transformação de suas práticas inadequadas. Tal forma de despertar a consciência crítica das falhas dos professores acaba conduzindo-os a um sentimento de desprofissionalização, que gera “angústias, sofrimentos e muitas decepções” (P1). A outra participante da pesquisa (P2) confirmou, também, a natureza improvisada (pautada em "erros" e "acertos") de uma prática pedagógica desvinculada de referências teóricas, científicas, recebidas de forma institucional. Se considerarmos as datas de conclusão das graduações cursadas (2005, Pedagogia, e 1988, Letras) e as datas das falas emitidas pelas docentes entrevistadas (2014), aflora a situação crítica de uma formação acadêmica 
precária, mantida ao longo das décadas de atuação profissional. Essas datas são significativas, já que apontam para as carências do Ensino Superior num passado longínquo (há 26 anos, no caso do Curso de Letras) e num passado mais próximo (há 09 anos, no caso do Curso de Pedagogia). Poderíamos esperar por um resultado mais produtivo, em termos de uma melhor qualificação docente para o ensino de leitura, no caso do curso ministrado mais recentemente (2005).

Teriam as Instituições de Ensino Superior (Faculdades, Centros Universitários e Universidades) clareza dessa formação teórica inadequada, repassada aos graduandos de Pedagogia e Letras, futuros formadores de leitores na Educação Básica? As IES vêm realizando uma avaliação do perfil profissional docente dos seus egressos? Há compromisso efetivo do Estado para uma formação eficiente (continuada) dos profissionais formadores de leitores?

A afirmação de Brito (2010, p. 242) de que, na graduação, formam-se "crenças" que, geralmente, são inconscientes, sobre a identidade do profissional futuro e sobre a natureza do conhecimento herdado, ficou comprovada nessa pesquisa. Na identificação, pelos participantes da pesquisa, das teorias que lhes servem de suporte atual na organização metodológica das suas aulas de leitura, fica reiterada a dificuldade de as docentes expressarem os pressupostos teóricos que lhes servem de suporte:

Acredito que tenho como suporte uma teoria construtivista, pois trabalho a leitura aplicando e levando em consideração o movimento metodológico (considerar conhecimentos prévios e compartilhar para repertoriar, ouvir e ler com autonomia).

FALA da P1 (Graduada em Pedagogia, em 2005).

FONTE: Dados da Pesquisa, 2014.

Além de explorar o estudo proposto no material professor/aluno (Proposta do Estado de São Paulo) utilizo outros meios como pesquisa na sala de leitura, consultando o acervo, pesquisa na internet, explorando todos os recursos midiáticos da escola e seus espaços.

FALA da P2 (Graduada em letras, em 1988).

FONTE: Dados da pesquisa, 2014.

Percebe-se que P1 inicia a sua fala afirmando que considera usar, como fundamentação teórica, na organização do seu trabalho pedagógico, a teoria piagetiana (cognitivista). Mas, ao declarar que leva em consideração, nas suas práticas, o "movimento metodológico", ressaltando a relevância dada aos "conhecimentos prévios", ao "compartilhar para repertoriar", à "autonomia", acaba revelando percepção do trabalho educativo como um processo de construção do conhecimento pautado, claramente, em Piaget, mas também vinculado a outras teorias de suporte histórico-cultural, por 
exemplo, a teoria bakhtiniana da Intertextualidade, que não chega a ser citada por ela. Tal desconhecimento docente, na Educação Básica, identificado na pesquisa, tem origem histórica, já que as teorias socioculturais entraram nos anos 1970 no Brasil, mas seus estudos ainda têm se mantido mais restritos aos círculos e grupos de pesquisa acadêmica, parecendo existir, como apontou Freitas (2004, p. 66), "uma hierarquia em relação à ciência e ao saber”, uma espécie de "estratificação do saber". De fato, as teorias socioculturais continuam desconhecidas dos professores da Educação Básica, como demonstram os resultados dessa pesquisa e de outros estudos, aqui informados. As duas profissionais desse nível de escolarização, apesar de uma ter cursado a graduação nos anos 1980, e a outra em décadas posteriores (anos 2000), ainda não conhecem essas teorias e não sabem aproximar ou diferenciar as propostas de natureza cognitivista piagetiana da tendência do cognitivismo sociointeracional vigotskiano e de suas contribuições no processo de formação de leitores críticos.

A fala de P2 não correspondeu ao que foi indagado na pesquisa; ou seja, ela não respondeu à solicitação de informações sobre as teorias utilizadas por ela para suporte na organização metodológica (atual) de suas aulas de leitura; limitou-se a mencionar materiais didáticos, como os ofertados pelo estado paulista: consulta a acervos, uso de outros recursos como a internet e de outros espaços midiáticos. Pelo conteúdo da resposta, percebe-se o não conhecimento da importância de uma definição prévia e clara dos pressupostos teóricos que vão nortear a prática pedagógica.

Os registros discursivos das participantes da pesquisa são reveladores de que as graduações não lhes permitiram condições de formação de um repertório teórico-crítico significativo nas áreas de atuação (Educação e Letras). Fato também importante a ser relatado é que, na "biblioteca do professor" da escola em que elas atuam, constam autores (estudiosos das teorias histórico-culturais) como, por exemplo, Oliveira (2013), que discute o processo bakhtiniano no desenvolvimento da aprendizagem; mas as professoras nem tinham conhecimento da existência dessa obra (e de outras) na biblioteca da Instituição em que trabalham há anos. Faltariam ações gestoras informativas e estimuladoras dessas leituras e discussões teóricas na própria escola?

Enfim, sobre o comprometimento da qualidade da prática docente das duas participantes da pesquisa, resultante de um repertório cultural deficitário (herdado das graduações e das formas continuadas de formação profissional ofertadas pelo Estado), destacamos: com relação à formação teórica vivenciada no período de realização das suas graduações: a) nenhuma experiência em Metodologias específicas de ensino de leitura; b) conhecimento teórico-científico (sobre texto, signo e significação) limitado a estudos da Linguística Clássica Saussuriana, e desconhecimento dos estudos 
pragmáticos e discursivos da Linguística Textual, das Teorias Materialistas da Linguagem, que ressaltam o texto como ato de linguagem, com destaque para sua natureza sociossemiótica; c) desconhecimento dos conceitos diferenciadores da natureza específica das linguagens (verbais e visuais; literárias e não literárias); d) ausência de exercícios de leitura estética das linguagens artísticas (verbais e visuais).

Com relação à autoavaliação das docentes sobre a própria prática, a formação nas graduações e ao longo do tempo de trabalho (30 e 25 anos), observamos: a) consciência da precária formação teórico-científica herdada das graduações e despertada, superficialmente, nas atividades (episódicas) de capacitação, atualização e extensão cultural; b) impossibilidade atual de, enquanto leitoras, identificarem teorias que lhes possam servir de suporte para organização metodológica das aulas; c) dificuldade de reconhecerem, nos modos de elaboração e organização das atividades sugeridas nos materiais didáticos (livros e cadernos do professor), os pressupostos teóricos que nortearam os objetivos da proposição das atividades; d) sentimento de solidão na prática docente: sujeição (segundo elas) a continuados "erros" e "acertos", próprios de um aprendizado individual, sofrido, desvinculado de referenciais teóricos institucionalizados e experiências compartilhadas; e) críticas às formas de funcionamento das capacitações ofertadas por Estados e Municípios: tempo insuficiente, não continuidade das ações, teorias difíceis para quem não recebeu formação anterior; f) confissão de um sentimento de angústia, gerado da frágil conscientização das falhas cometidas no trabalho pedagógico, alertadas, geralmente, por docentes universitários, convidados para eventos rápidos que acabam não possibilitando a transformação de caminhos metodológicos no cotidiano escolar.

No que se refere ao desempenho de leitura das duas docentes, foram registrados: a) o desempenho trivial de um leitor limitado às coleções didáticas (adotadas) e a alguns paradidáticos (materiais, em geral, insuficientes para formação teórica, crítica, necessária à organização e avaliação da própria prática); b) nenhuma participação em pesquisa teórico-científica (durante e após as graduações cursadas), nem mesmo práticas de leituras teóricas esporádicas ou participação eventual em discussões em grupos de pesquisa institucional.

\section{Considerações finais}

Do perfil docente configurado nessa pesquisa, emerge a reflexão final: se existe uma significativa produção de pesquisa em Educação (sobre ensino de leitura no Brasil), qual a razão de 
persistir, ainda, o mesmo quadro de dificuldades, equívocos, carências teóricas, sentimentos de solidão e angústia dos professores (da Educação Básica), envolvidos, no país, com a formação de leitores? O desafio de vencer essa problemática estaria na própria complexidade desse conteúdo escolar (ensino de leitura)? Afinal, ler é complexo. Ou estaria no silêncio dos profissionais desse nível de escolarização, intimidados diante dos gestores e impactados pelo medo de exposição da precariedade do seu saber (intelectual), de sua autoformação pedagógica (solitária) e de suas práticas cotidianas resultantes (segundo eles) de "erros" e "acertos" individuais?

A nosso ver, nas práticas extensivas acadêmicas, é preciso ouvir mais esses profissionais e não continuar a silenciá-los, diante de falas impactantes de especialistas da Educação, que deles acabam se distanciando, pela posição hierárquica de um saber intelectual privilegiado. Não podemos continuar aceitando que docentes da Educação Básica, com experiência profissional de 25/30 anos continuem a desconhecer Vigotski, Bakhtin e outros autores e estudiosos das teorias histórico-culturais da Linguagem, se os pesquisadores das Universidades continuam a estudá-los intensamente! Não é possível torná-los leitores críticos da própria prática (nos anos 2000) se, como comprovaram as falas das docentes participantes da pesquisa, os únicos referenciais teóricos dos quais elas se lembram são os utilizados, no Brasil, sobretudo nos anos 1970, nos quais predominavam teorias do "empirismo", do "racionalismo" e não do “interacionismo social” (DEL RÉ, 2009, p. 18).

Uma maior qualificação do ensino de leitura no Brasil aponta, necessariamente, para o desafio de um investimento institucional articulado (Estado, Universidade/Faculdade e Escola Básica) na formação identitária cultural, científica e pedagógica do professor. Cabe às Instituições de Ensino Superior a verificação do desempenho profissional de seus egressos, contribuindo, de forma mais interventiva, na melhoria de suas práticas cotidianas e construindo, já nas graduações, o perfil investigador dos graduandos, para torná-los, profissionalmente, críticos das próprias práticas (futuras). Cabe, também, ao Estado, a revisão de suas práticas formativas, de natureza esporádica.

Consideramos que essas iniciativas institucionais articuladas poderão alcançar os resultados objetivados coletivamente, desde que todos os níveis educacionais (Educação Básica, Graduações, PósGraduações Lato e Stricto Sensu) dialoguem de forma produtiva, de modo que as Graduações não percam o contato com os seus egressos (atuantes na Educação Básica); que a Pós-Graduação Lato Sensu não constitua apenas mais um curso com conteúdos temáticos desvinculados das necessidades reais dos docentes da Educação Básica; que as pesquisas da Pós-Graduação Stricto Sensu não se utilizem dos professores das redes de ensino somente como sujeitos das suas investigações científicas, 
mas que os envolvam como atores em Projetos de Pesquisa - Ação de natureza crítica e colaborativa; que os resultados das pesquisas acadêmicas, além de serem disseminados nos meios científicos, originem formas interventivas de transformação das práticas escolares da Educação Básica.

Com certeza, esses diálogos educacionais, aqui destacados, pressupõem uma cadeia de relações sociais e culturais mais complexas (de natureza legal, governamental, interinstitucional, política, econômica, ideológica) e nos conduzem a outras reflexões igualmente significativas, que constituiriam conteúdos temáticos para um outro estudo.

\section{Notas}

${ }^{1}$ Nesse estudo, foi utilizada a décima sexta edição da obra "Marxismo e Filosofia da Linguagem", publicada no Brasil, São Paulo: Hucitec, 2014, que, conforme nota dos tradutores brasileiros, foi baseada na tradução francesa (Paris: Les Éditions de Minuit, 1977) e, em parte, na tradução americana (Nova York/ Londres: Seminar Press, 1973); mas os tradutores esclarecem que, de forma indispensável, foram necessárias, também, consultas à edição original da obra (1929), assinada por Volochínov. Na introdução do livro (16.ed.), Marina Yaguello (p. 11-9) faz uma revisão histórica e discussões sobre a inclusão dos nomes de V. N. Volochínov e de P. N. Medviédiev (sobretudo Volochínov) no processo autoral da produção bakhtiniana.

${ }^{2}$ Pesquisa docente (acadêmico-científica), com Parecer Favorável do CEP (CONEP) 266.239 - Data do relatório: 07/05/2013, de acordo com a Resolução CNE no 466/ 2012 (Ética na Pesquisa com Seres Humanos), desenvolvida no Programa de Pós-Graduação/Mestrado em Educação na Universidade do Oeste Paulista - Presidente Prudente - SP.

\section{REFERÊNCIAS}

ANDRÉ, Marli Eliza Dalmazo Afonso de. Estudo de caso em pesquisa e avaliação educacional. 3. ed. Brasília: Liber Livro, 2008.

APARECIDA (P1). Entrevista (Escrita). Presidente Epitácio - SP., 13 março. 2014.

BAKHTIN, Mikhail (Volochínov). Marxismo e filosofia da linguagem. 16. ed. Tradução: Michel Lahud e Yara Frateschi Vieira. Colaboração: Lúcia Teixeira Wisnik e Carlos Henrique D. Chagas Cruz. São Paulo: HUCITEC, 2014.

BAKHTIN, Mikhail. Estética da criação verbal. São Paulo: Martins Fontes, 2003.

BENVENISTE, Émile. Problemas de linguística geral. São Paulo: Nacional, 1976.

BRITO, Eliana Vianna Kozma. O processo de interação nas aulas de leitura: crenças e expectativas do professor em formação. In: SIMÕES, Darcília Marindir Pinto; MELO, Eliana Menezes de. (Orgs.) Linguagens, criatividade e sentidos: pelos percursos da semiótica do cotidiano. Rio de Janeiro: Dialogarts, 2010, p. 241 - 254. 
CASTORINA, José Antonio; FERREIRO, Emília; LERNER, Delia; OLIVEIRA, Marta Kohl de. Piaget/ Vygotsky: novas contribuições para o debate. 3. ed. São Paulo: Ática, 1996.

CHARTIER, Roger. A história cultural: entre práticas e representações. Tradução: Maria Manuela Galhardo. Rio de Janeiro: Bertrand Brasil, 1990.

CHIAPPINI, Ligia. (Coord.). Aprender e ensinar com textos. 2. ed. São Paulo: Cortez, 1988.

DEL RÉ, Alessandra. (Org.) Aquisição da linguagem: uma abordagem psicolinguística. São Paulo: Contexto, 2009.

DEL RÉ, Alessandra; PAULA, Luciane de; MENDONÇA, Marina Célia (Orgs.). A linguagem da criança: um olhar bakhtiniano. São Paulo: Contexto, 2014.

DUBAR, Claude. A socialização: construção das identidades sociais e profissionais. São Paulo: Martins Fontes, 2005.

ECO, Umberto. Tratado geral de semiótica. Tradução: Antônio de Pádua Danesi e Gilson Cardoso de Souza. São Paulo: Perspectiva, 1980.

ECO, Umberto. Semiótica e filosofia da linguagem. Tradução: Mariarosaria Fabris e José Luiz Fiorin. São Paulo: Ática, 1991.

FERREIRA, Homero. O perfil do professor como responsável pelo "Programa Sala de Leitura" em escolas públicas de uma cidade do oeste paulista: formação e práticas de mediação. 2016. $108 \mathrm{f}$. Dissertação (Mestrado em Educação) - Universidade do Oeste Paulista - UNOESTE, Presidente Prudente, 2016.

FREITAS, Maria Teresa de Assunção. O pensamento de Vygotsky e Bakhtin no Brasil. 6. ed. Campinas: Papirus, 1994. (Coleção Magistério: Formação e Trabalho Pedagógico)

GROSSI, Elvair (org.); GEROLDO, Nanci; BAFFA, Alda Mendes. Diálogos bakhtinianos: Bakhtin no texto, na literatura e na sala de aula. São Paulo: Porto de Ideias, 2011.

HYPOLITO, Álvaro Moreira. Trabalho docente e profissionalização: sonho prometido ou sonho negado? In: VEIGA, Ilma Passos Alencastro; CUNHA, Maria Isabel da (Orgs.), Desmistificando a profissionalização do magistério. Campinas: Papirus, 1999, p. 81-100.

IMBERNÓN, Francisco. Formação docente e profissional: formar-se para a mudança e a incerteza. 8. ed. São Paulo: Cortez, 2010.

KLEIMAN, Angela. Aspectos cognitivos da leitura. 11. ed. Campinas: Pontes, 2008.

KOCK, Ingedore G. Villaça. O texto e a construção dos sentidos. 8. ed. São Paulo: Contexto, 2005. 
KOCK, Ingedore G. Villaça. Ler e compreender os sentidos do texto. 3. ed. São Paulo: Contexto, 2010.

KOCK, Ingedore G. Villaça; BENTES, Anna Christina; CAVALCANTE, Mônica Magalhães. Intertextualidade: diálogos possíveis. 3. ed. São Paulo: Cortez, 2012.

KRISTEVA, Julia. Introdução à semanálise. Tradução: Lúcia Helena França Ferraz. São Paulo: Perspectiva, 1974.

MARCUSCHI, Luiz Antônio. Produção textual, análise de gênero e compreensão. São Paulo: Parábola Editorial, 2008.

MERRIAN, Sharan B. Case Study Research in Education. San Francisco: Jossey Bass, 1988.

NÓVOA, Antonio. Les temps des professeurs. Analyse socio-historique de la profession enseignante au Portugal (XVIII - XX siède). Lisboa: Instituto Nacional de Investigação Científica, 1987. v. 2.

OLIVEIRA, Marta Kohl de. Vygotsky aprendizado e desenvolvimento: um processo sócio-histórico. 2. ed. São Paulo: Scipione, 2013.

PARISOTTO, Ana Luzia Videira; TREVIZAN, Zizi. Leitura e produção de texto no ensino fundamental: uma experiência colaborativa. In: ENCONTRO NACIONAL DE DIDÁTICA E PRÁTICAS DE ENSINO, 16. UNICAMP, 2012, Campinas. Anais...Campinas - SP: Junqueira \&Marin Editores, Livro 2, 2012. p. 1233-43

PÊCHEUX, Michel. Semântica e discurso: uma crítica à afirmação do óbvio. Tradução: Eni P. Orlandi e outros. Campinas: UNICAMP, 1988.

PIMENTA, Selma Garrido; ANASTASIOU, Lea das Graças Camargo. Docência no ensino superior. 5. ed. São Paulo: Cortez, 2004.

REIS, Carlos; LOPES, Ana Cristina M. Dicionário de teoria da narrativa. São Paulo: Ática, 1988, p. 27-30.

SÃO PAULO (Estado). Secretaria da Educação. Fundação para o Desenvolvimento da Educação. Ler $e$ Escrever: coletânea de atividades. Guia de Planejamento e Orientações Didáticas - Professor $4^{\circ}$ ano. 2. ed. São Paulo: FDE, 2010.

SÃO PAULO (Estado). Currículo do Estado de São Paulo: linguagens, códigos e suas tecnologias. 2. ed. São Paulo: SEE, 2010.

SÃO PAULO (Estado). Material de apoio ao currículo do Estado de São Paulo: caderno do professor, língua portuguesa, ensino médio, $1^{\text {a }}$ série. São Paulo: SEESP 2014

SÃO PAULO (Estado). Material de apoio ao currículo do Estado de São Paulo: caderno do aluno, língua portuguesa, ensino médio, $1^{\text {a }}$ série. São Paulo: SEESP, 2014. 
SAUSSURE, Ferdinand. Curso de linguística geral. 26. ed. Tradução: Antônio Chelini, José Paulo Paes e Izidoro Blikstein. São Paulo: Cultrix: 1995.

SILVA, Ezequiel Theodoro. A leitura no contexto escolar. 5. ed. São Paulo: FDE, 1988.

SILVA, Ezequiel Theodoro. A produção da leitura na escola: pesquisas x propostas. São Paulo: Ática, 2003.

SMOLKA, Ana Luiza Bustamante; NOGUEIRA, Ana Lúcia Horta (Orgs.). Estudos na perspectiva de Vigotski: gênese e emergência das funções psicológicas. Campinas: Mercado de Letras, 2013. (Série Desenvolvimento Humano e Práticas Culturais).

SOARES, Magda. Linguagem e letramento. 2. ed. São Paulo: Contexto, 2004.

TARDIF, Maurice. Saberes docentes e formação profissional. Petrópolis: Vozes, 2002.

TREVIZAN, Zizi; SAMPAIO, Desireé Lorane Negrão. Docência e pesquisa na educação básica: a importância da análise documental de livros didáticos. Cadernos de Educação, Pelotas, n. 49, p. 60-75, set./dez. 2014.

TREVIZAN, Zizi; LOPES, Eduardo dos Santos; SOUZA, Renata Junqueira. O discurso fotográfico no livro didático: representações e práticas inadequadas de leitura. Discursos Fotográfico, Londrina, v. 11, n. 19, p. 247- 72, jul./dez. 2015.

TREVIZAN, Zizi. O papel mediador do professor no ensino da leitura literária. In: CONGRESSO INTERNACIONAL DE LITERATURA INFANTIL E JUVENIL, 4. Universidade Estadual Paulista "Júlio de Mesquita Filho" - UNESP e Centro de Estudos em Leitura e Literatura Infantil e Juvenil "Maria Betty Coelho Silva" - CELLIJ. 2015, Presidente Prudente. Anais... Presidente Prudente: UNESP/CELLIJ; v. 1, p. 1427-39, 2015.

VAILLANT, Denise; MARCELO, Carlos. Ensinando a ensinar: As quatro etapas de uma aprendizagem. Tradução: Márcia dos Santos Lopes. Curitiba: UTFPR, 2012.

VYGOTSKY, Lev Semenovitch. Psicologia del arte. Barcelona: Barral Editores, 1972.

VIGOTSKI, Lev Semenovitch. Pensamento e linguagem. 3. ed. Tradução: Jefferson Luiz Camargo. São Paulo: Martins Fontes, 2005.

XAVIER, Libânia Nacif. A construção social e histórica da profissão docente. Revista Brasileira de Educação. Rio de Janeiro: ANPED/Autores Associados, v. 19, n. 19, p. 827-849, out./ dez. 2014.

ZÉLIA (P2). Entrevista (Escrita). Presidente Epitácio - SP., $13 \quad$ março. 2014. 


\section{Scientific Knowledge and Epistemology of \\ Practice in Institutional Processes of \\ Educating Teachers and Readers}

\begin{abstract}
This study analyzes the education of basic education teachers at institutions of higher education and in continuing professional experiences. The research uses a qualitative methodology (semi-structured interviews) and discusses the educational trajectory and professional experiences of two reading teachers in São Paulo state, Brazil who were accredited in language sciences and pedagogy. It uses a Bakhtinean theoretical framework as reference and a historical-cultural approach. The findings reveal the lack of theoretical and practical training for reading teachers and indicate the need for coordinated investments by the state, university and schools in the formation of teachers' cultural, scientific and pedagogical identities to enhance a more effective performance in the education of critical readers.
\end{abstract}

Key words: Higher Education and Scientific Knowledge. Basic Education and Epistemology of Practice. Reader Education.
Conocimientos científicos y epistemología de la práctica en los procesos institucionales de formación docente y de formación de lectores

\section{Resumen}

Con el fin de repensar el proceso de formación de los profesores de la Educación Básica, configurado en la vida cotidiana de las instituciones de educación superior y en la experiencia profesional continuada, la investigación presentada en este artículo utiliza una metodología cualitativa (entrevistas semiestructuradas) analizando la historia de la educación y las experiencias de dos profesoras, graduadas en Letras y Pedagogía que trabajan en la enseñanza de la lectura, en el Estado de São Paulo, Brasil. El estudio tiene como referencia teórica bakhtiniano, de características históricas y culturales, y presenta en su muestra, la necesidad práctica y teórica del profesional formador de lectores. Las conclusiones apuntan un desafío de realizar una inversión articulada (Escuela Primaria, Universidad, Estado) en la formación de la identidad (cultural, científica, pedagógica) del maestro, para llevar a cabo de manera más efectiva el proceso de formación de lectores críticos.

Palabras clave: Educación Superior y el Conocimiento Científico. Educación Básica y Epistemología de la Práctica. Formación de Lectores.

Recebido em: 08/12//2015

Aprovado em: 28/08/2016
Zizi Trevizan

E-mail: zizi_trevizan@uol.com.br

PERSPECTIVA, Florianópolis, v. 35, n.1, p. 237-261, jan./mar. 2017

http://www.perspectiva.ufsc.br 